

\section{The Curious Incident of the Dog in the Night-time}

by Mark Haddon. 2004.

Publisher: Vintage Books, London.

Tom Hughes, Katharine Harding

Department of Neurology, University Hospital of

Wales, Cardiff, UK

At this month's book club, Mark Haddon's portrayal of 15-year-old Christopher-who has Asperger's syndrome-generated lively discussion. We heard exchanges about how health professionals could adapt their consultation styles for people with social cognition disorders, how they might better understand how people with Asperger's feel in company-the author's arresting description of being viewed through a one-way mirror was helpfully harrowing-and the importance of appreciating that some people have very unreliable channels of communication between their feelings, emotions, thoughts and actions. To be is to be perceived: but if you are unsure how people perceive you, and you cannot reliably perceive others, the world is a puzzling and relentlessly threatening place.

Christopher is the book's narrator. He lives with his father. He knows a lot about mathematics (he loves prime numbers and uses them to number his chapters) but very little about human beings. He loves lists, patterns and the truth. He hates the colours yellow and brown, and does not like being touched. Mrs Shears lives next door. One day Christopher sees her dog on her lawn. "It looked as if it was running on its side, the way dogs run when they think they are chasing a cat in a dream. But the dog was not running or asleep. The dog was dead. There was a garden fork sticking out of the dog." He uses logic and strategy to solve the crime, enduring the accusation that he was responsible, and relates the disturbing things he discovers along the way. He is motivated by a pure and unsullied desire to solve a mystery, Sherlock Holmes style. His approach is doggedly disinterested and thanks to his persistence the truth soon starts to trickle out.

The book seems as much about the problems and relationships of apparently normal adults as it is about people with Asperger's syndrome. The adults in Christopher's life use their capabilities to show compassion, sympathy and remorse but also use deceit, obstruction, disguise and concealment. Christopher's social skills are profoundly limited in comparisonand to some extent are elicited by this mismatch — but they do allow him to be very successful in his own eyes, and to make the most of his more limited abilities.

It is a very readable story with several lessons for clinical practice, most importantly, that we may need to modify our communication skills in ways that can feel unnatural, if we are to help patients like Christopher. At one point, his father has to tell him something unpleasant and looks out of the window as he does so, which Christopher finds comforting as it allows him to listen to what was being said without being distracted by facial expressions or eye contact. He also finds concrete forms of communication the most comprehensible, and his teacher frequently communicates with him in this way. His father also finds alternative gestures of love that do not require an uncomfortable level of physical contact, to which Christopher can respond. If we are uncertain how best to communicate with patients like Christopher, we can learn from their families, who understand them best, and speak to them in a way that they can best understand and reply.

This book should be compulsory reading for anyone trying to understand the seemingly insurmountable challenge faced by people with problems like Asperger's syndrome, and the profound implications for them, their parents and their carers. As an exercise in distinguishing disability from handicap, and the effect of context and environment on both, it is worth reading again. As a reminder of the importance of trying to see the world from the perspective of others, it is a masterpiece, and should always be at hand. 